\title{
Directive action required
}

\author{
Europe's handling of applications to grow genetically modified crops amounts to bad governance.
}

$$
\left.\right|_{m} ^{\operatorname{tin}}
$$
$\mathrm{t}$ took many years of acrimonious debate for the European Union (EU) to agree a directive regulating the cultivation of genetically modified (GM) crops. In many member countries, the public was ready to accept genetic technologies in the service of medicine but not, as they saw it, in the service of the agricultural industry. That industry, aggressively in favour of GM crops, continues to be powerful and influential. European publics remain strongly opposed.

There was extensive consultation in formulating the directive, and science was recruited in support of each side. But six years after it was passed, not a single application has been approved for cultivation. Many EU countries are showing their continuing distaste for GM crops by refusing to grow the only one currently approved (authorized before the new rules came into effect), Monsanto's MON810 insect-resistant maize (corn). And last month, environment commissioner Stavros Dimas prepared to reject applications for two varieties of insect- and herbicide-resistant maize, from Syngenta and Pioneer Hi-Bred International, by inappropriately overturning the recommendation of his scientific advisers (see page 928).

This all highlights the problematic framework within the EU bodies. The approval process calls on the commission to make a sciencebased decision, gives member states the chance to decide politically on that science-based decision and then, if they can't agree, leaves the final decision entirely up to the commission. In the current cases, the commission is at war with itself, with powerful commissioners such as those for agriculture and industry trying to get Dimas to change his mind and recommend approval of the two crop varieties.

Dimas has misused science to tip the balance of his analysis of risks and benefits with which he justified his decision. Central to the process is the European Food Safety Authority (EFSA), which operates independently of the commission and the member states, and is mandated with securing independent scientific advice for them. Dimas is free to seek further, or even alternative, scientific advice. But his draft decision cites 11 papers purportedly demonstrating environmental risk that were published during the shamefully long period that the EFSA's report sat on his desk, without evaluating them in the context of the body of scientific literature. He has declined to respond to questions about how this selection of publications was made. This is neither in the letter nor the spirit of the directive. His decision to say 'no', where the EFSA said 'yes', is a political, not a scientific, move.

At this point, whatever the commission proposes in terms of these two crop applications, the member states are unlikely to be able to decide with the necessary majority one way or the other. And so the infighting commission will make the final decision.

The directive needs to be revised to ensure that the checks and balances put in place to reassure opponents, while not crushing innovation, cannot be abused by the political motives of one side. Most importantly, scientific input must be handled appropriately. So the proposal of German agriculture minister Horst Seehofer for a single agency dedicated to such tasks, which makes decisions based only on must be handled appropriately."
"Scientific input science and does not need to send every application for individual political approval, makes sense. This won't happen soon given the politics, but there is every reason to support the idea.

Scientists and others cannot reiterate too often that crops optimized to particular environments by genetic enhancement will be of significant benefit to societies in rich and poor countries, for example by increasing yields, allowing crops to grow in poorly fertile regions and reducing the amount of external chemical control required to maintain a healthy crop. The available evidence indicates that their potential for damaging the environment is small. Rigorous sciencebased risk assessment is likely to favour the cultivation of GM crops, subject to appropriate surveillance.

But whatever science indicates, member states want to protect their veto rights on crop applications because of opposition to GM crops by their publics. Benefits from the technology can be expected to become more apparent, for example in cheaper and better foods, or locally grown foods that help prevent famine. Until that time, advocates will need to persist against a strong political tide. Meanwhile, a directive that makes the fate of such crops dependent on the conflicted perspectives of individual commissioners is failing and needs repair.

\section{Hollow victory}

\section{More benign global AIDS statistics do not mean that the battle against HIV is being won.}

\footnotetext{
$\mathrm{n}$ a rare piece of good news, the Joint United Nations Programme on HIV/AIDS (UNAIDS) last month cut its estimate of the number of people infected with HIV worldwide. The revised figures brought the estimate of those infected down from 39.5 million to 33.2 million, and put the number of new infections for 2007 at 2.5 million, down
}

from what the agency now says was a late-1990s peak of more than 3 million per year. The revised statistics are particularly encouraging for India, where the agency says that 2.5 million people are infected with HIV, a figure that is less than half its previous estimate.

But most of this change is accounted for by more accurate sampling techniques, and the new numbers sadly reflect little significant progress in combating AIDS on the ground. That is especially true in sub-Saharan Africa where UNAIDS reports that $68 \%$ of all HIV infections and $76 \%$ of AIDS deaths now occur. In these countries, women are often unable to insist on condom use, concurrent relationships contribute to the spread of the disease, and fewer than one-third 